UMTRI-2006-31

SEPTEMBER 2006

\title{
Recent Changes in Headlamp Illumination DiRected Toward Traffic SignS
}

\author{
Michael SivaK \\ BRANDON SCHOETTLE \\ Michael J. FlanNAgaN
}

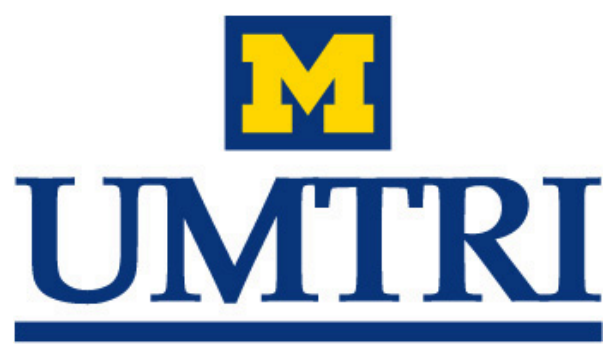

UNIVERSITY OF MICHIGAN

TRANSPORTATION RESEARCH INSTITUTE 


\title{
RECENT CHANGES IN HEADLAMP ILLUMINATION DIRECTED TOWARD TRAFFIC SIGNS
}

\author{
Michael Sivak \\ Brandon Schoettle \\ Michael J. Flannagan
}

The University of Michigan

Transportation Research Institute

Ann Arbor, Michigan 48109-2150

U.S.A.

Report No. UMTRI-2006-31

September 2006 
Technical Report Documentation Page

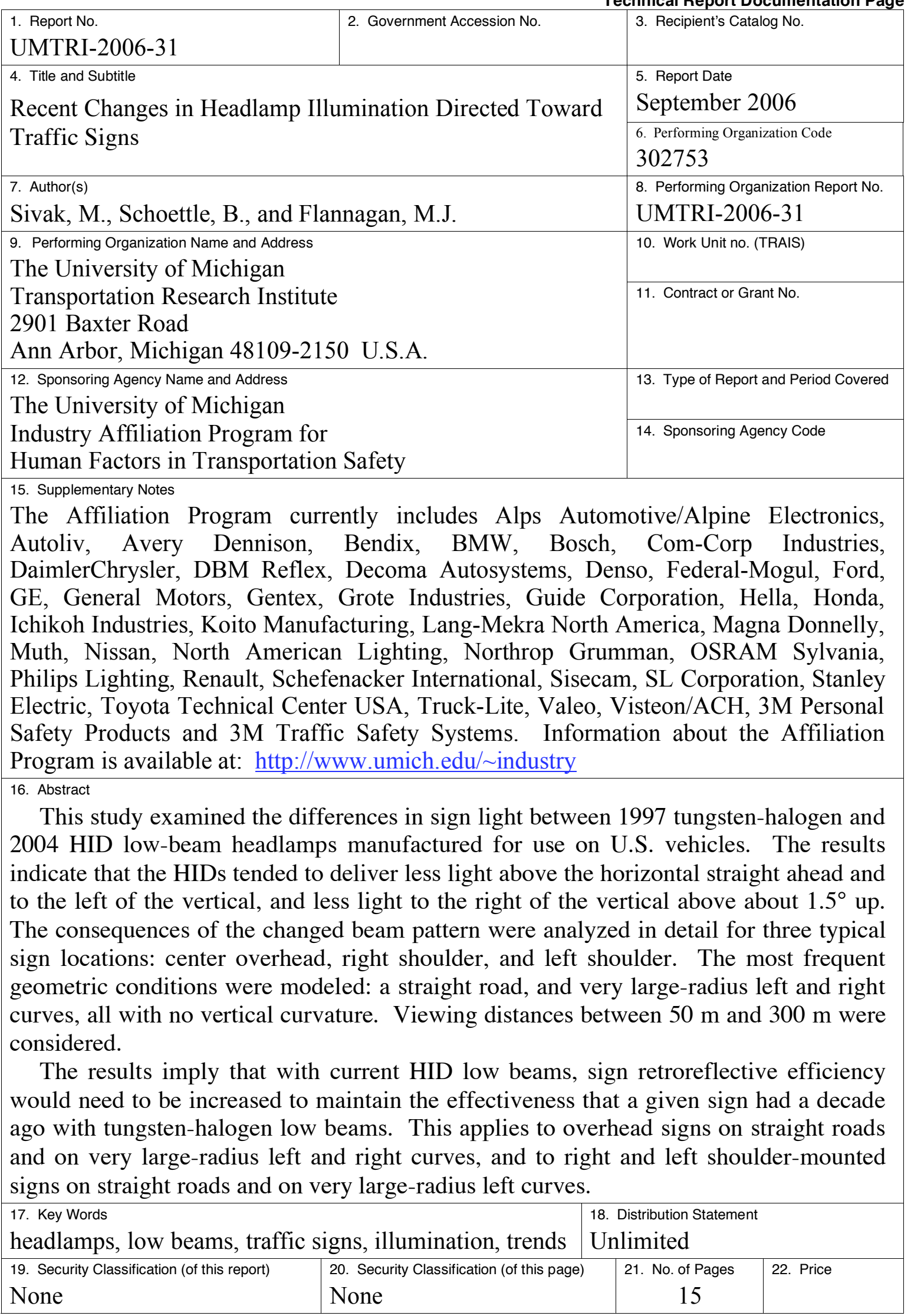




\section{Acknowledgment}

Appreciation is extended to the members of the University of Michigan Industry Affiliation Program for Human Factors in Transportation Safety for support of this research. The current members of the Program are:

\begin{tabular}{|c|c|}
\hline Alps Automotive/Alpine Electronics & Koito Manufacturing \\
\hline Autoliv & Lang-Mekra North America \\
\hline Avery Dennison & Magna Donnelly \\
\hline Bendix & Muth \\
\hline BMW & Nissan \\
\hline Bosch & North American Lighting \\
\hline Com-Corp Industries & Northrop Grumman \\
\hline DaimlerChrysler & OSRAM Sylvania \\
\hline DBM Reflex & Philips Lighting \\
\hline Decoma Autosystems & Renault \\
\hline Denso & Schefenacker International \\
\hline Federal-Mogul & Sisecam \\
\hline Ford & SL Corporation \\
\hline $\mathrm{GE}$ & Stanley Electric \\
\hline General Motors & Toyota Technical Center, USA \\
\hline Gentex & Truck-Lite \\
\hline Grote Industries & Valeo \\
\hline Guide Corporation & Visteon/ACH \\
\hline Hella & 3M Personal Safety Products \\
\hline Honda & 3M Traffic Safety Systems \\
\hline
\end{tabular}

Ichikoh Industries 


\section{Contents}

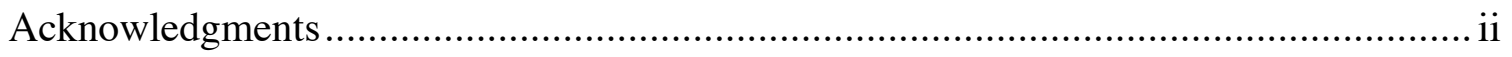

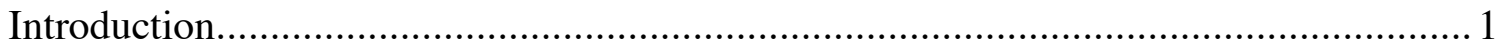

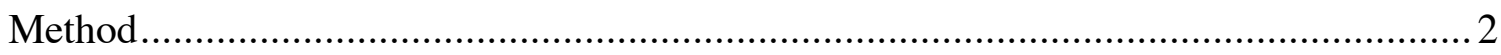

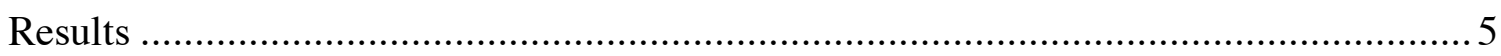

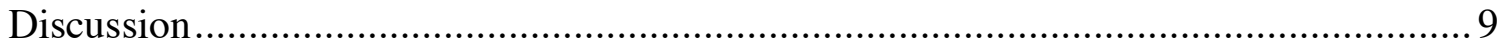

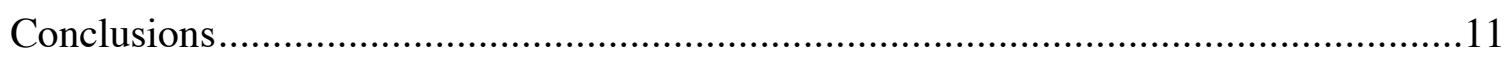

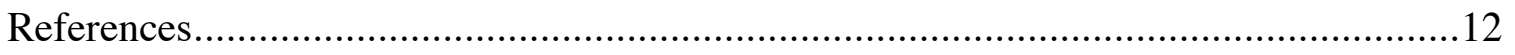




\section{Introduction}

Vehicle low-beam headlighting in the U.S. has recently undergone major changes. First, there was the introduction in 1997 of visual/optical aiming, which tended to result in sharper vertical gradients and consequently less light above the horizontal. Second, there has been an increased usage of projector lamps, again favoring shaper vertical gradients. Third, there has been a gradual increase in the use of HID light sources, resulting in more available luminous flux. (Waiting in the wings is another light source - LED — with the first headlighting introduction slated for 2007.)

Since 1997, we have periodically documented the changes in the resulting beam patterns by photometering samples of headlamps (Sivak, Flannagan, Kojima, and Traube, 1997; Sivak, Flannagan, and Miyokawa, 2000; Schoettle, Sivak, and Flannagan, 2001; Schoettle, Sivak, Flannagan, and Kosmatka, 2004; Sivak, Schoettle, and Flannagan 2004). The present study compares our oldest tungsten-halogen sample (for model year 1997 vehicles) with our newest HID sample (for model year 2004 vehicles).

The focus in this analysis is on changes in illumination directed toward retroreflective traffic signs-devices that rely on headlamp illumination for their nighttime performance. Such an analysis is relevant because of the continuing parallel improvements in the retroreflective efficiency of the sheeting materials available for traffic signs. 


\section{Method}

\section{Headlamp samples}

The 1997 tungsten-halogen sample (Sivak et al., 1997). A total of 23 lamps, manufactured for use on 1997 model year vehicles, constituted this sample. These lamps were manufactured for use on 23 vehicles: the 15 best-selling cars, and the 8 best-selling light trucks and vans in the U.S. for the first 9 months of the 1997 model year. The 23 vehicles constituted $45 \%$ of all vehicles sold during that time period.

The 2004 HID sample (Sivak et al., 2004). This sample consisted of 5 lamps manufactured for use on 2004 model year vehicles. Tables 1 through 3 compare the two samples in terms of light sources, optics, and aiming methods.

Table 1

Light sources used in the lamps in the two samples. The entries are percentages.

\begin{tabular}{|l|c|c|}
\hline \multicolumn{1}{|c|}{ Light source } & 1997 tungsten-halogen & 2004 HID \\
\hline \hline HB1 (9004) & 9 & \\
\hline HB2 (9003) & 13 & \\
\hline HB4 (9006) & 34 & \\
\hline HB5 (9007) & 44 & 40 \\
\hline D2R & & 60 \\
\hline D2S & & \\
\hline
\end{tabular}

Table 2

Optics of the lamps in the two samples. The entries are percentages.

\begin{tabular}{|l|c|c|}
\hline \multicolumn{1}{|c|}{ Light source } & 1997 tungsten-halogen & 2004 HID \\
\hline \hline Reflector & 33 & 40 \\
\hline Lens & 67 & \\
\hline Projector & & 60 \\
\hline
\end{tabular}


Table 3

Specified aiming method of the lamps in the two samples. The entries are percentages.

\begin{tabular}{|l|c|c|}
\hline \multicolumn{1}{|c|}{ Aiming method } & 1997 tungsten-halogen & 2004 HID \\
\hline Mechanical & 75 & \\
\hline VHAD & 25 & \\
\hline VOL & & 80 \\
\hline VOR & & 20 \\
\hline
\end{tabular}

\section{Approach}

We calculated the combined luminous intensities from the two headlamps directed toward the forward scene. The calculations assumed a headlamp mounting height of $0.66 \mathrm{~m}$ and a lamp separation of $1.20 \mathrm{~m}$ (Schoettle, Sivak, and Nakata, 2002). The comparisons were based on the median $\left(50^{\text {th }}\right.$ percentile $)$ combined luminous intensities for each lamp sample.

\section{Road geometric profile}

Three horizontal road curvatures were considered: a straight road, and very largeradius left and right curves. The particular radius selected $(506 \mathrm{~m})$ corresponds to the minimum radius for Class A curves (FHWA, 2005). Only very large-radius curves were considered because they, along with straight roads, correspond to the vast majority of all road segments (MDOT, 2000). For all conditions, level roads were assumed.

\section{Sign locations}

Three typical sign locations were examined in detail: left shoulder, center overhead, and right shoulder. The locations are specified in Table 4.

\section{Viewing distances}

Six viewing distances were analyzed: 50, 100, 150, 200, 250, and $300 \mathrm{~m}$. 
Table 4

The mounting heights and lateral offsets of the three sign locations examined in detail.

\begin{tabular}{|l|c|c|}
\hline \multicolumn{1}{|c|}{ Sign location } & Mounting height & $\begin{array}{c}\text { Lateral offset from the } \\
\text { center of the lane }\end{array}$ \\
\hline \hline Left shoulder & $2.44 \mathrm{~m}(8 \mathrm{feet})$ & $-9.75 \mathrm{~m}(-32$ feet $)$ \\
\hline Center overhead & $6.10 \mathrm{~m}(20 \mathrm{feet})$ & $0 \mathrm{~m}(0 \mathrm{feet})$ \\
\hline Right shoulder & $2.44 \mathrm{~m}(8 \mathrm{feet})$ & $6.10 \mathrm{~m}(20$ feet $)$ \\
\hline
\end{tabular}




\section{Results}

Figure 1 shows the differences between the median 2004 HID luminous intensities and the median 1997 tungsten-halogen luminous intensities for the central part of the beam pattern (from $20^{\circ}$ left to $20^{\circ}$ right and from $5^{\circ}$ down to $7^{\circ}$ up). As is evident from Figure 1, HID low beams tend to provide (1) more light below the horizontal (except for a small area centered at $2.5^{\circ}$ right and $2^{\circ}$ down), (2) less light above the horizontal straight ahead and to the left of the vertical, and (3) less light to the right of the vertical above about $1.5^{\circ}$ up.

Figure 1 also presents the trajectories of the three sample signs on a straight roadway. Separate trajectories are presented from the perspective of the left headlamp and the right headlamp.

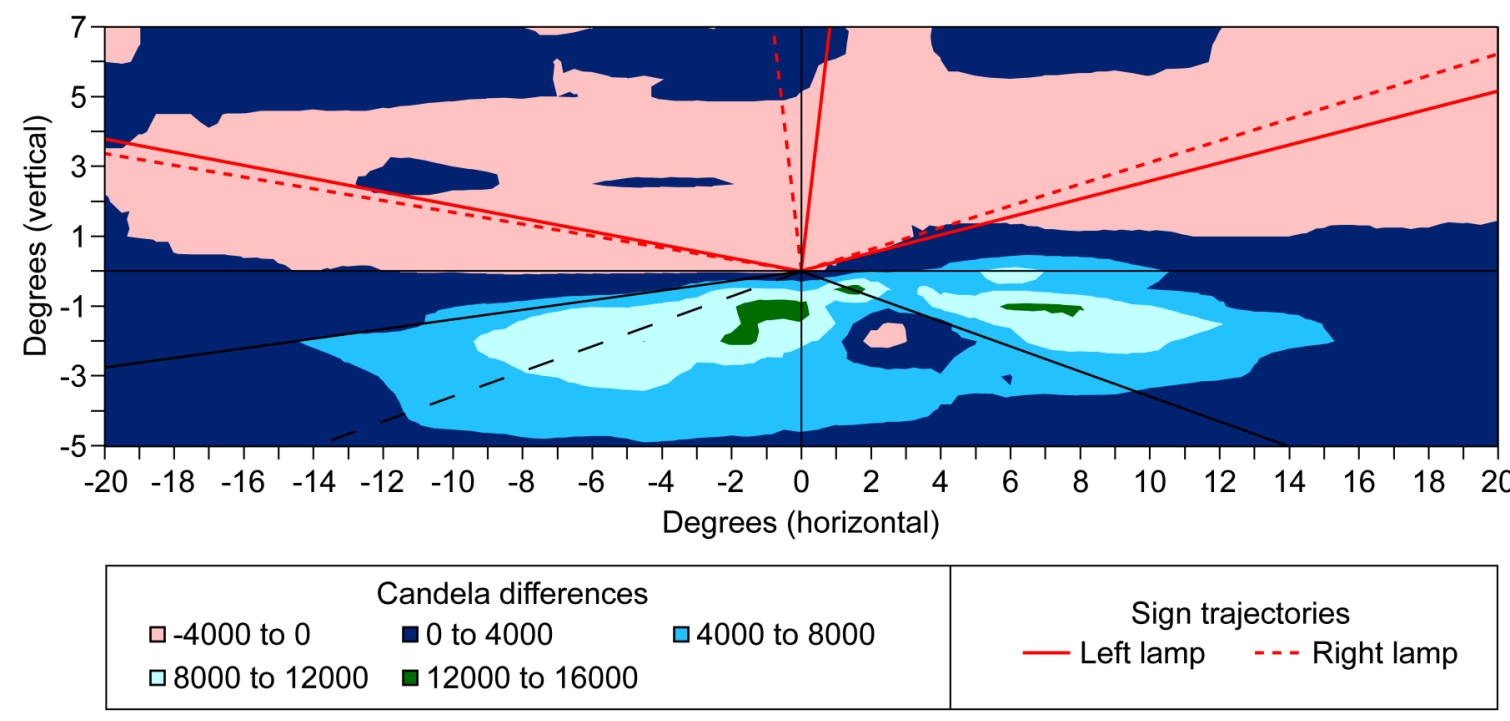

Figure 1. Differences between the median 2004 HID luminous intensities and the median 1997 tungsten-halogen luminous intensities for the central part of the beam pattern (2004 HID minus 1997 tungsten-halogen). The solid lines below the horizontal represent the edges of a straight and level roadway with two 3.7-m wide lanes. The dashed line below the horizontal represents the road midline. The colored lines above the horizontal illustrate the trajectories of the three signs of interest from the perspective of the left headlamp and the right headlamp, respectively. 
Table 5 presents the calculations of the combined luminous intensities from the two lamps directed toward the three sample sign locations on straight roads. Specifically, the entries in Table 5 are the median combined luminous intensities from the 2004 HID low beams as percentages of the median combined luminous intensities from the 1997 tungsten-halogen low beams.

The information in Table 5 indicates that, in comparison to the 1997 tungstenhalogen low beams, there are substantial reductions of luminous intensity directed from HID low beams toward these signs, with the greatest reductions for the overhead sign. For this sign, reductions were present for all but the shortest distance, with the maximum reduction of $69 \%$. For the sign on the left shoulder, reductions were present for all distances, with the maximum reduction being 39\%. The reductions for the sign on the right shoulder were greatest for the shortest distance tested (31\%), with no reductions for intermediate distances.

Table 5

Luminous intensity directed toward traffic signs on a straight road from 2004 HID low beams as a percentage of luminous intensity from 1997 tungsten-halogen low beams.

\begin{tabular}{|c|c|c|c|}
\hline \multirow{2}{*}{ Distance $(\mathrm{m})$} & \multicolumn{3}{|c|}{ Sign location } \\
\cline { 2 - 4 } & Left shoulder & Overhead & Right shoulder \\
\hline \hline 50 & $87 \%$ & $111 \%$ & $69 \%$ \\
\hline 100 & $61 \%$ & $72 \%$ & $110 \%$ \\
\hline 150 & $71 \%$ & $59 \%$ & $99 \%$ \\
\hline 200 & $79 \%$ & $68 \%$ & $81 \%$ \\
\hline 250 & $75 \%$ & $44 \%$ & $92 \%$ \\
\hline 300 & $72 \%$ & $31 \%$ & $94 \%$ \\
\hline
\end{tabular}


Tables 6 and 7 document the changes in luminous intensities directed towards the three sign locations on the two curves. On the left curve (see Table 6), HID low beams provide less illumination for all three sign positions (except for the left shoulder signs at the two longest distances, the overhead sign at the nearest distance, and the right shoulder sign at the longest distance). The maximum reductions were $29 \%, 22 \%$, and $64 \%$ for the left shoulder, overhead, and right shoulder, respectively.

Table 6

Luminous intensity directed toward traffic signs on a 506-m radius left curve from 2004 HID low beams as a percentage of luminous intensity from 1997 tungsten-halogen low beams.

\begin{tabular}{|c|c|c|c|}
\hline \multirow{2}{*}{ Distance $(\mathrm{m})$} & \multicolumn{3}{|c|}{ Sign location } \\
\cline { 2 - 4 } & Left shoulder & Overhead & Right shoulder \\
\hline \hline 50 & $87 \%$ & $135 \%$ & $68 \%$ \\
\hline 100 & $71 \%$ & $82 \%$ & $36 \%$ \\
\hline 150 & $75 \%$ & $80 \%$ & $61 \%$ \\
\hline 200 & $88 \%$ & $91 \%$ & $68 \%$ \\
\hline 250 & $108 \%$ & $80 \%$ & $85 \%$ \\
\hline 300 & $216 \%$ & $78 \%$ & $102 \%$ \\
\hline
\end{tabular}

On the right curve (see Table 7), HID low beams provided less illumination for the overhead sign, except at the longest distance tested. The maximum reduction was $48 \%$. For the right shoulder location, the reduction was present only at the shortest distance (a reduction of 26\%); for the left shoulder sign the reductions were confined to the two shortest distances, with a maximum reduction of $67 \%$. Indeed, at the intermediate and long distances, HID headlamps provided substantially more illumination for the two shoulder signs, with the maximum increases of $336 \%$ and $485 \%$, respectively. 
Table 7

Luminous intensity directed toward traffic signs on a 506-m radius right curve from 2004 HID low beams as a percentage of luminous intensity from 1997 tungsten-halogen low beams.

\begin{tabular}{|c|c|c|c|}
\hline \multirow{2}{*}{ Distance $(\mathrm{m})$} & \multicolumn{3}{|c|}{ Sign location } \\
\cline { 2 - 4 } & Left shoulder & Overhead & Right shoulder \\
\hline \hline 50 & $79 \%$ & $92 \%$ & $74 \%$ \\
\hline 100 & $33 \%$ & $52 \%$ & $110 \%$ \\
\hline 150 & $194 \%$ & $74 \%$ & $416 \%$ \\
\hline 200 & $585 \%$ & $77 \%$ & $436 \%$ \\
\hline 250 & $535 \%$ & $89 \%$ & $323 \%$ \\
\hline 300 & $416 \%$ & $119 \%$ & $382 \%$ \\
\hline
\end{tabular}




\section{Discussion}

This study examined the differences in light output between 1997 tungstenhalogen and 2004 HID low beams manufactured for use on U.S. vehicles. The HID low beams tended to provide more light down the road, especially just below the horizontal. This trend is very welcome, because an increase in illumination in this area should help drivers avoid pedestrians and other obstacles. However, the HIDs tended to deliver less light above the horizontal straight ahead and to the left of the vertical, and less light to the right of the vertical above about $1.5^{\circ}$ up. This trend has important negative consequences on the visibility and legibility of retroreflective traffic signs, because such signs rely on headlamp illumination for their nighttime performance.

The consequences of the changed beam pattern were analyzed in detail for three typical sign locations: center overhead, and right and left shoulders. The most frequent geometric conditions were modeled: a straight road, and very large-radius $(506 \mathrm{~m})$ left

and right curves, all with no vertical curvature. Viewing distances between $50 \mathrm{~m}$ and $300 \mathrm{~m}$ were considered.

Overhead sign. The HID low beams delivered less light toward this location than did tungsten-halogen low beams a decade ago. This pattern was present for all distances tested, except for the shortest distance $(50 \mathrm{~m})$ on the straight road and on the left curve, and the longest distance $(300 \mathrm{~m})$ on the right curve. The maximum reduction was $69 \%$.

Sign on the right shoulder. For this location, the HIDs produced less usable light at most of the viewing distances on the straight road and the left curve. The maximum reduction was $64 \%$. On the right curve, however, the HID lamps tended to produce substantially more light, consistent with the general pattern of the HIDs having more light output on the right side of the beam pattern below about $1.5^{\circ}$ up.

Sign on the left shoulder. For this location, the HIDs produced less usable light at all viewing distances on the straight road, and all but the two longest distances (250 and $300 \mathrm{~m}$ ) on the left curve. On the right curve, the reductions were confined to the two shortest distances (50 and $100 \mathrm{~m}$ ). Overall, the greatest reduction was $67 \%$. 
Other sign locations. This analysis focused on three specific sign locations. However, the information in Figure 1 can be used to infer the effects of the changed illumination on signs in other locations for straight roads. Increasing the mounting height of a sign (be it a shoulder-mounted or overhead sign) would increase the slope of its trajectories in Figure 1, and vice versa. Analogously, increasing the lateral offset of a sign would decrease the slope of these trajectories, and vice versa. As is evident from Figure 1, the general patterns of the results that we obtained for the three specific locations on a straight road apply to a wide range of sign mounting heights and lateral offsets. 


\section{Conclusions}

The proportion of HID headlights in the U.S. market has lagged behind those in Europe and Japan (e.g., Hamm, 2004). Furthermore, HIDs will soon face LEDs as a new competitor for market share. (The photometric performance of LED headlamps has not yet been documented.) However, to the extent that HIDs will likely increase their penetration in the U.S. market, the present analysis provides guidance for sign manufacturer and users who aim to maintain the net performance of their signs. Specifically, the present results imply that with current HID low beams, sign retroreflective efficiency would need to be increased to maintain the effectiveness that a given sign had a decade ago with tungsten-halogen low beams. This applies to overhead signs on straight roads and very large-radius left and right curves, and to right and left shoulder-mounted signs on straight roads and very large-radius left curves. 


\section{References}

FHWA [Federal Highway Administration]. (2005). HPMS [Highway Performance Monitoring System] field manual. Washington, D.C.: Office of Highway Policy Information, Federal Highway Administration.

Hamm, M. (2004). HID headlamp development: Performance benchmark, market penetration and future styling developments in world's markets (SAE Technical Paper Series No. 2004-01-1283). Warrendale, PA: Society of Automotive Engineers.

MDOT [Michigan Department of Transportation]. (2000). Highway Performance Monitoring System field data (unpublished). Lansing, MI: Michigan Department of Transportation.

Schoettle, B., Sivak, M., and Flannagan, M.J. (2001). High-beam and low-beam headlighting patterns in the U.S. and Europe at the turn of the millennium. (Technical Report No. UMTRI-2004-23). Ann Arbor: The University of Michigan Transportation Research Institute.

Schoettle, B., Sivak, M., Flannagan, M.J., and Kosmatka, W.J. (2004). A market-weighted description of low-beam headlighting patterns in the U.S: 2004. (Technical Report No. UMTRI-2001-19). Ann Arbor: The University of Michigan Transportation Research Institute.

Schoettle, B., Sivak, M., and Nakata, Y. (2002). The locations of signaling and lighting equipment on passenger vehicles sold in the U.S. (Technical Report No. UMTRI-20028). Ann Arbor: The University of Michigan Transportation Research Institute.

Sivak, M., Flannagan, M.J., Kojima, S., and Traube, E.C. (1997). A market-weighted description of low-beam headlighting patterns in the U.S. (Technical Report No. UMTRI-97-37). Ann Arbor: The University of Michigan Transportation Research Institute.

Sivak, M., Flannagan, M.J., and Miyokawa, T. (2000). A first look at visually aimable and harmonized low-beam headlamps (Technical Report No. UMTRI-2000-1). Ann Arbor: The University of Michigan Transportation Research Institute.

Sivak, M., Schoettle, B., and Flannagan, M.J. (2004). Recent trends in the performance of tungsten-halogen and HID low beams in the U.S. (Technical Report No. UMTRI-200425). Ann Arbor: The University of Michigan Transportation Research Institute. 